\title{
Uma crítica da economia da informação na era das mídias digitais
}

\author{
José Luís Garcia \\ É doutor em Sociologia e investigador \\ principal do quadro do Instituto de \\ Ciências Sociais da Universidade \\ de Lisboa. Sua bibliografia inclui: \\ La Contribution en ligne: Pratiques \\ participatives à l'ère du capitalisme \\ informationnel (co-editor com S. Proulx \\ e L. Heaton) (2014); Jacques Ellul and \\ the Technological Society in the 21st \\ Century (co-editor com H. M. Jerónimo \\ e C. Mitcham) (2013).
}

Resumo: Colocando no centro as novas tecnologias da informação, este artigo procura oferecer uma breve interpretação crítica do processo que, nos limiares do século XXI, tem revolvido a economia, a tecnologia, a comunicação e a sociedade. Argumenta-se que a nova realidade se encontra estabelecida por duas dinâmicas que se cruzam: as novidades tecnológicas permanentes nas formas de criação e distribuição de comunicação e informação; e as tendências econômicas orientadas para a transformação de importantes dimensões do conhecimento, da cultura e da comunicação, reduzidos à forma digital em produtos destinados para um mercado global, competitivo e repleto de novas possibilidades de crescimento. O processo que vários apelidam de informacionalização da sociedade intensifica a mercantilização crescente dessas esferas, doravante povoadas por conceitos como criatividade, inovação e competitividade.

Palavras-chave: Economia política da informação; Mídias digitais; Sociedade de informação.

\section{Title: A critique of the information economy in the age of digital media}

Abstract: With the new information technologies as its focus, this article offers a brief critical interpretation of how the economy, technology, communication and society have been upturned in the early years of the twenty-first century. It argues that two intersecting dynamics define the new reality: permanent technological innovation in the ways communication and information are generated and distributed; and economic trends directed towards transforming significant aspects of knowledge, culture and communication, reduced to their digital forms, into products aimed at a global, competitive market which is full of new growth potential. The process which is increasingly called the "informationalization" of society accentuates the commodification of those areas, henceforth populated by concepts such as creativity, innovation and competitiveness.

Keywords: Political economy of information; Digital media; Information society. 


\section{Introdução}

Entre o final do século XIX e as primeiras décadas do século XX ocorreu um processo de grandes transformações que envolveu um surto de urbanização, o surgimento de novas indústrias, a constituição de mercados nacionais, movimentos migratórios massivos e novas vias e meios de transporte à escala nacional e internacional. Como mostrou Park (1923) em seu célebre artigo sobre a "história natural do jornal", aqueles acontecimentos estiveram estreitamente ligados a outra mudança - a passagem da imprensa doutrinária, com poucos leitores, para os jornais com notícias e publicidade que mostraram ter capacidade para dominar a informação e tornarem-se um poderoso intermediário social. Salienta-se ainda que, nas sociedades agitadas por essa dinâmica, muitos aspectos da vida econômica, cultural e social se conformaram à lógica do mercado e dos valores mercantis.

As mutações referidas podem ser consideradas um preâmbulo das metamorfoses que irromperam na alvorada do séculoXXI e que deram origem às chamadas cidades globais, à mundialização de dimensões completas da economia, à reestruturação da atividade econômica através da desregulação das economias nacionais e ao concurso de um novo tipo de atividade científica, a tecnociência orientada para o interesse privado. Essa tecnociência esteve na base da formação de novas esferas de negócio, como o ciberespaço e os biomercados. A remodelação do contexto informacional, estimulada pelo que se tem apelidado de revolução digital, criando vastas redes de informação que ligam indivíduos, empresas, entidades políticas e Estados, aparece novamente como um fator de relevo. Note-se que o acesso de mais de um terço da população mundial à Internet tornou esse meio, em poucos anos, na mais global das tecnologias da informação e comunicação da história. A mundialização do último século aglutina uma mistura complexa de interesses econômicos e de ideias bem-intencionadas. Além disso, é importante acrescentar que grande parte da dinâmica tecnológica do século XX coabitou com o desenvolvimento dos mercados e do comércio mundial. Dando ênfase às novas tecnologias da informação, este texto procura oferecer uma breve interpretação crítica do processo que, nos limiares do século XXI, tem revolvido a economia, a tecnologia e a informação.

\section{Da ideia de sociedade de informação à capitalização do conhecimento}

Essas transformações têm gerado interpretações assentes na concepção de que estamos nos umbrais de uma era de informação impulsionada por máquinas inteligentes. Mas um apontamento dessa ideia, mesmo que sumário, pode recuar à década de 1940 e destacar a visão pioneira de Norbert Wiener, matemático estadunidense e pai da cibernética, que pensou a comunicação como uma característica do ser humano e um dispositivo de mudança da sociedade. Inspirado pela concepção devedora do legado da "máquina de Turing" de que a inteligência é fundamentalmente um meio de tratamento e de troca de informação, usou essas noções para descrever toda a atividade inteligente e interação social. Para Wiener (1954), a comunicação reveste-se do papel de gestora da vida comum, sendo os conflitos provocados por problemas de ordem informacional. Em sua "sociedade da comunicação", a informação circularia sem entraves, seja de poder ou dinheiro, impedindo o embargo, o segredo, a desigualdade do acesso e a transformação da informação em mercadoria, constituindo assim um meio de resolução das tensões, do estímulo à partilha, e de eliminação das desordens humanas. Racionalidade e transparência seriam os ideais dessa sociedade. $O$ imaginário utópico dessa visão da comunicação tem sido muito questionado por

${ }^{1}$ Ver Breton (1992). vários autores, ${ }^{1}$ que desnudaram a promessa de uma nova sociedade baseada em fundações tecnicistas e na ficção que se estabelece ao redor delas.

É importante destacar que a ideia de sociedade da comunicação encontrou também eco na visão prospectiva do sociólogo Daniel Bell nas obras The End of 
Ideology (1960) e The Comming of Post-Industrial Society (1973), onde teorizou uma alteração estrutural das sociedades ocidentais. O quadro conjectural proposto por Bell previa a expansão rápida do setor de serviços e a valorização pelo mercado das competências teóricas e técnicas, aspectos definidores de uma nova ordem na organização do trabalho e da produção. É essa nova disposição econômica e social, surgida lentamente no pós-guerra, que o conceito de "sociedade pós-industrial" procurou traduzir. Bell diagnosticou o "fim da ideologia" como característica central da sociedade pós-industrial, onde as "doutrinas organizacionais" de gestão social assumiriam um papel regulador. 0 prefixo "pós" significa que a sociedade nascente estava observando uma ruptura, ainda que parcial - pois preservava traços residuais -, face à estrutura precedente.

Recordando Bell (1973), na sociedade pré-industrial a vida era um jogo contra a natureza, onde o indivíduo trabalhava na base de sua potência muscular; na era industrial a máquina predominava e a existência era técnica e racionalizada, e a vida era um jogo contra a natureza fabricada; na sociedade pós-industrial o jogo ocorreria entre indivíduos em um contexto onde predominaria uma variedade de serviços que empresas especializadas prestariam a outras empresas, como serviços informáticos, financeiros, de formação profissional, de marketing, consultoria e gestão, auditoria etc. Insinua-se assim a desmaterialização do processo de acumulação e a correlativa importância de fatores intangíveis como a informação e o conhecimento. Bell (1960/1973) convergiu com a ideia de "economia da informação" desenvolvida pelos economistas Machlup (1962) e Porat (1977), que diagnosticaram na economia estadunidense a emergência de um novo setor, quaternário, voltado para a formação e oferta de informação ao mercado. Se até a década de 1980 a ideologia econômica dominante enfatizava a capacidade produtiva - sobretudo industrial, com o investimento em capital fixo e na interpretação dominante das economias pós-industriais -, a ênfase passou a ser colocada no processo de aquisição e gestão do conhecimento, associado à gestão da informação. Para descrever esse princípio motor da nova economia, onde a inovação técnica e científica, assim como a inovação em políticas sociais, é fundada sobre a codificação de conhecimentos teóricos, foi introduzida a noção de "sociedade do conhecimento" -retomada, por exemplo, por Stehr (1994) e Dunning (2000) -, que é geralmente usada enquanto sinônimo do conceito de "sociedade da informação".

A década de 1970, que começa marcada pelo choque da crise petrolífera de 19711973, sinaliza também o início de um ciclo de prosperidade - prosperidade essa, é importante realçar, que ocorrerá simultaneamente com os primeiros movimentos de inversão da tendência do último século para maior igualdade de distribuição de renda. A falência do regime fordista conduziu os governos ocidentais a recorrerem às novas tecnologias como meio de reanimação do capitalismo debilitado. É nesse contexto, enquanto se consolidava a concorrência econômica e geopolítica entre os Estados Unidos da América, a União Europeia e o Japão, que se destacou a utilização da ideia de sociedade da informação por meio do trabalho de Yonegi Masuda (1980), que a apresentou em sua forma utópica mais pura. Segundo esse autor, os sistemas anteriores da tecnologia inovadora estiveram sempre focados no poder produtivo material, mas anunciava-se agora um novo tipo de sociedade humana, cuja força matricial seria a produção de valores de informação e não de valores materiais. Se a primeira revolução industrial foi combinada ao espírito do renascimento, do humanismo e materialismo para concretizar uma sociedade orientada para o consumo de massa, Masuda (1980) postula que a nova revolução informacional seria consonante com o novo pensamento holista, que valorizaria a simbiose entre comunidades, a sinergia humanos-máquinas e uma nova espiritualidade para produzir a nova sociedade de criação e de conhecimento de massa. $O$ espírito da sociedade da informação seria o espírito do globalismo, onde o homem e a natureza viveriam em harmonia, consistindo eticamente em autodisciplina estrita e contribuição social. Essa nova sociedade seria atravessada 
por movimentos comunitários voluntaristas que utilizariam as novas tecnologias em nome de aspirações de autonomia e autodesenvolvimento individual e coletivo. Como é facilmente constatado, mesmo que as estratégias financeiras ocupem agora o primeiro plano, a globalização tem um filão idealista ligado ao sonho de um planeta imbuído de expansão e disseminação da informação e cultura.

No final do século XX, a economia afastava-se dos setores produtivos baseados em petróleo, automóveis e na motorização e procurava domínios capazes de sustentar um novo ciclo de crescimento da riqueza. O quadro no qual surgiram e se desenvolveram as tecnologias da informação contribuiu para definir suas características de força, ao mesmo tempo científica, tecnológica, industrial e mercantil. Impelidas pelo crescimento econômico, tornaram-se uma das instâncias modeladoras da economia, mostrando seu potencial enquanto indústria fornecedora de novos produtos e modos de produção, abrindo novos mercados e concentrando investimentos. A organização econômica observou uma inflexão cognitiva, onde a informação se estabeleceu como nova matéria-prima. Mais do que ser um acontecimento novo, o elemento cognitivo das economias pósfordistas da transição do século XX para o século XXI tornou-se estrutural.

Na década de 1990, o conceito de sociedade da informação encontrava-se já bastante aceito, sendo nesse período plenamente adotado. Em 1995, a reunião do G7 em Bruxelas vem articular o horizonte da sociedade da informação com a problemática da globalização, introduzindo pela primeira vez a noção da "sociedade global da informação". Confirmou-se desse modo, primeiramente, que a questão da informatização ganhou todo o seu sentido quando conjugada com as perspectivas de desenvolvimento de um mercado mundial; depois, que o problema crucial das desigualdades de acesso às tecnologias da informação não pôde mais ser negligenciado a partir do momento em que foi pensado a nível global. A universalização da noção de "sociedade da informação" tornouse corrente para descrever um mundo de onipresença midiática, da exposição massiva à informação, de fluxo instantâneo de informação no espaço e de um vasto conjunto de novas tecnologias - em especial a internet, mas incluindo também a televisão, tanto a aberta como a a cabo-, entre outras. Essas tecnologias abrangem um enorme potencial na criação de uma nova classe de engenheiros $\mathrm{e}$ técnicos, que engendram um modo de pensar funcional e novo.

Para compreender melhor essa mudança, convém esclarecer que a nova realidade do século XXI encontra-se estabelecida por duas dinâmicas que se cruzam: as novidades tecnológicas permanentes nas formas de criação e distribuição de comunicação e informação; e as tendências econômicas dirigidas para a transformação de importantes dimensões do conhecimento, da cultura e da comunicação, reduzidas à forma digital em produtos destinados para um mercado global, competitivo e repleto de novas possibilidades de crescimento. O processo que vários apelidam de informacionalização da sociedade intensifica a mercantilização crescente dessas esferas, doravante povoadas por conceitos como inovação, criatividade e competitividade.

Configura-se assim uma avalanche de novos produtos e modos de divulgação, referentes ao conhecimento, informação, cultura, espetáculo, entretenimento, sociabilidade e ao estético, criada pelas capacidades de transmutabilidade e divulgação digital, pela força dos novos conglomerados empresariais e pelo imperativo da utilidade comercial e do negócio aplicado a essas áreas. Florescem então as chamadas indústrias criativas. Ao aumentar a produção com uso intensivo de conhecimento e de procedimentos criativos, de máquinas "analíticas" e de bens e serviços ricos em informação, marketing e publicidade, cresce também o número de mercadorias que passa a associar-se ao universo informacional. Simetricamente, ao movimento de capitalização do conhecimento/informação corresponde a propensão para a economia apresentar uma característica digital. 
É possível afirmar que a economia do século XXI opera uma transfiguração do capitalismo, deslocando o centro operativo dos recursos materiais e bens de consumo para eleger como motor o horizonte de possibilidades digitais. É nesse panorama que se compreende o protagonismo assumido pelas novas tecnologias de informação, a par da constelação de novos valores de mercado que ultrapassam largamente a esfera dos bens consumíveis. Publicidade, comunicação e recursos humanos são hoje dimensões capitais de uma economia que tem como pilares a tecnociência e a informação. Os produtos/mercadorias digitais são cada vez mais intensivos em conhecimento científico e técnico e em "informação" (em todas as fases de identificação, extração, processamento, produção e distribuição de bens/serviços econômicos de todos os tipos). A intensidade crescente de energia, capital, conhecimento/ "informação" tem sido acompanhada por coeficientes semelhantes de intensidade em design, em uma certa esteticização difusa das mercadorias e em marketing, cujos custos se equiparam muitas vezes à soma de todas as outras fases econômicas do processo de produção, ou até as ultrapassam.

A nova ordem econômica que a sociedade de informação institui é sustentada em uma nova lógica de produção e consumo. A massificação de bens e serviços em rede - com exemplos paradigmáticos como o telefone celular, o e-mail e as redes sociais - configura uma nova dinâmica de mercado, estruturalmente assente na conectividade. Novas características distintivas despontam no paradigma econômico da era digital, como as externalidades de consumo e a multiplicação de efeitos de rede. $O$ valor e a utilidade dos bens flutuam agora de acordo com o número de utilizadores de um mesmo serviço, ou de produtos similares e compatíveis. Os circuitos de produtos complementares introduzem um novo imperativo de consumo. $O$ consumidor de bens divisíveis, de fabricação industrial, cedeu lugar ao consumidor de sistemas (MARTINS; GARCIA, 2013).

\section{Uma nova configuração social entre ciência, tecnologia e mercado}

O percurso das tecnologias de informação ilustra como, no processo de alargamento e aprofundamento do mercado, os novos setores tecno-econômicos surgiram de uma nova conformação entre ciência, tecnologia e mercado. A partir dos anos 1980, a interpenetração entre aqueles três domínios observou uma transformação que colocou o campo científico-tecnológico sob a pressão do direcionamento mercantil sistemático. Esse acontecimento teve como corolário a emergência de uma nova ordem valorativa dos cientistas, um novo horizonte legitimador da ciência, novos modos de produção dos conhecimentos e de organização e o financiamento das instituições que os suportam. Assim, o mercado de trabalho transfigura-se em um novo mercado de conhecimento.

Dessa forma, o novo capitalismo subtrai da informação a função de bem social para pensá-la como mercadoria, que combina aspectos simbólicos (cultura, linguagem, imagem), biológicos (desde a descoberta de uma sequência precisa da molécula de $A D N$ ) e econômicos. O princípio da mutação, orientado pelo valor negocial e pelo imperativo da rentabilidade, tem retirado a informação da retórica justificativa dos bens sociais para assumi-la como bem de mercado, transacionável e consumível.

A política de comunicação e cultura apresenta-se progressivamente subalternizada às dimensões mercantil e industrial e ao imperativo da gestão lucrativa. Exacerba-se a tensão entre a busca por lucro e a necessidade de as sociedades democráticas contarem com um sistema de informação que sirva ao espaço político democrático. O número de empresas que possuem e controlam a parte central de todos os produtos midiáticos diminuem, surgindo questões perturbadoras sobre o conceito, a propriedade e o controle de informação, e também sobre a concentração de poder e o rumo do jornalismo. A internet, sobretudo por meio das publicações digitais, da blogosfera e de outras formas de informação online, como os motores de busca, irrompe como expectativa 
de modos alternativos e libertadores de informação, conhecimento, interação e colaboração. Muitos acreditam que as transformações em curso, em particular as que dizem respeito às tecnologias da informação e comunicação, são promissoras quanto ao estabelecimento de um campo mais vasto de conhecimento e até de uma sociedade civil global. No entanto, existem sinais suficientes de que o desenvolvimento da internet está restabelecendo vários dos principais problemas políticos que as mídias tradicionais já tinham apontado, indicando que a mudança do meio técnico não é suficiente para os solucionar.

O acordo relativo à ideia de "sociedade de informação" induziu respostas críticas, segundo as quais a saturação semântica que o conceito de "sociedade global da informação" conheceu, o que se deve majoritariamente à disseminação de seu uso pelos principais governos das sociedades industrializadas, que as outras acolheram em seguida. Essa colonização conceptual teria desencadeado uma corrida à informatização, tanto no norte como no sul. Críticos como Mattelart (2000), Ramonet (1998/1999) e Norris (2001) sublinham que as atividades fundadas no conhecimento e geradoras de riqueza não se dispersam uniformemente pelo mundo, sendo que as tecnologias da informação, longe de atenuarem o fosso norte-sul, contribuiriam para o aprofundar. A longo prazo, a apropriação da capacidade técnica no hemisfério norte, sobretudo no domínio do software, impediria que as nações do sul desenvolvessem suas bases autônomas, e dessa forma os países mais pobres e periféricos enfrentariam ao mesmo tempo severas ameaças à sua autonomia cultural (RÉNAUD; TORRES, 1998). Segundo essa perspectiva, a designação de "sociedade da informação" politizou-se, passando a ser encarada como uma espécie de lema para as estratégias dos governos das grandes potências e grandes indústrias promoverem a consolidação necessária à afirmação do movimento de globalização dos mercados e da livre circulação de dados financeiros e comerciais, revestindo de um certo fatalismo economicista os efeitos da ocidentalização do mundo, encabeçada pela superpotência norteamericana (MATTELART, 1999, 2001). Mais do que uma realidade, a sociedade da informação global é sobretudo uma imagem do futuro (PROULX, 2008); em outras palavras, é um projeto ideológico e político e um horizonte técnico com o qual a maioria dos governos procura se alinhar, antecipando um futuro que à força de ser repetido pode acabar naturalizando-se nos discursos públicos.

Se é certo que as novas tecnologias de informação e comunicação encerram oportunidades e possibilidades de desenvolvimento, é importante não nos iludirmos quanto à natureza do seu potencial: não é certo, imediato, e nem garantido por qualquer dispositivo tecnológico. As oportunidades vislumbradas no ambiente digital quanto à distribuição e circulação da informação parecem muitas vezes comprometidas pela tendência verificada para a concentração do capital. Além disso, vale a pena mencionar a distinção entre acesso e usos, pois a classificação dicotômica inicial - que antagonizava aqueles que tinham acesso e posse aos excluídos do seu alcance -, está ultrapassada, sendo abstraída de qualquer uso efetivo. De fato, a realidade multiforme no universo das novas tecnologias de informação desmente esse simplismo.

É no ambiente profissional dos técnicos e da gestão que se encontram os mais entusiastas de uma visão pouco reflexiva acerca das possibilidades de uma cidadania digital e da partilha da esfera de mediação comunicacional, que antes era assegurada principalmente pelos jornalistas. Ocupados com preocupações comerciais, eles não dispõem de tempo nem de muita vontade para refletir sobre as implicações sociais, culturais e éticas dessas tecnologias. Muitos autores das ciências sociais também têm mostrado complacência com um discurso que não se interessa seriamente pelos limites e ambiguidades das tecnologias e pelas atuais relações de desequilíbrio entre tecnologia, cultura, direito e técnicas anteriores, ou mostrado demasiada tranquilidade quanto aos donos do poder que são responsáveis pelas mudanças tecnológicas ou os que estão se apropriando das 
contribuições gratuitas dos utilizadores da internet. Não é dada a necessária importância às relações entre tecnologia e mercadorização, ao rumo atual de apropriação privada dos saberes e ao sentido da alteração na regulação dos direitos de propriedade sobre o conhecimento. $O$ entendimento que possuem de tecnologia restringe-se a uma noção instrumental dos produtos, sendo-lhes desconhecida a tecnologia como força social e cultural, cujo impacto na cultura contemporânea não pode ser considerado como neutro em termos de valores.

Os processos de mercantilização e privatização tendem a subsumir esses aspectos simbólicos da criação cultural única dos objetos comunicacionais e culturais. Nesse sentido, os resultados em bens comunicacionais e culturais de difícil estandardização são incertos, onde os elementos qualitativos e subjetivos são mais relevantes que os quantitativos e não há livre mobilidade de capitais por diversas razões (exclusividade dos direitos de propriedade intelectual). E mesmo quando há mercado, inclusive sob condições de crescente internacionalização em certos segmentos, ele é muito unidirecional (norte-sul) e desigual, ainda existindo limites ou barreiras de entradas culturais, identitárias ou idiomáticas para a circulação igual dos objetos culturais e comunicacionais no mundo. Disso resulta a necessidade de uma crítica econômica da comunicação e da cultura.

Não é negado que por meio da edição de comentários em notícias, do aumento das modalidades de acesso à informação, da prática de escrita dos blogues, da disponibilização de imagens na internet, e entre outras formas de criar e distribuir informação, emergem novos espaços de liberdade, participação e configurações que poderão enriquecer a esfera pública. Mas, simultaneamente, assistimos nas últimas décadas a confluência de possibilidades dos novos meios digitais, que estão sendo capturados para fins de enriquecimento de alguns e de aumento de poder, e os modelos de gestão transgressores das especificidades da atividade informativa. A indiferenciação dos conteúdos conduz ao hibridismo crescente entre informação e entretenimento, sendo a especificidade do conhecimento diluída na grande quantidade de fragmentos de informação.

É importante frisar que todas as novas possibilidades de informação implicam acréscimo de responsabilidade social, para a qual a atividade mediadora, profissional e rigorosa do jornalista foi uma componente indispensável. As exigências da reconfiguração da indústria da mídia, impulsionadas pelas novas capacidades de obter e conceber produtos de tipo informativo, estão imprimindo uma lógica que tende para a negação da distinção substancial entre o jornalismo e as atividades emergentes de produção de conteúdos para as mídias, por meio da capacidade de transmutar a esfera informativa e pela multiplicação de suportes, plataformas e meios.

A opulência informativa que caracteriza o ambiente comunicacional contemporâneo não é apenas a expressão de abundância de conteúdos, onde qualquer busca ou interesse teriam garantias de satisfação. Pelo contrário, o universo comunicacional opulento é também um lugar de descomedimento, desordem, ruído, redundância e fragmentação. Esse universo acolhe, inexoravelmente, os riscos da desinformação, da contaminação entre dados e conteúdos, dos abusos publicitários. A abundância informativa, sem mecanismos de filtro baseados em coordenadas de relevo, credibilidade e precisão, permite a amálgama entre informação crível e erro grosseiro, conteúdos fúteis e imprecisos. O contexto comunicacional atual impõe rupturas com os capítulos precedentes da cognição humana, com alterações profundas na economia da memória e da atenção. O novo padrão de compreensão e interação é determinado pela dispersão rápida entre estímulos e tarefas, pela incapacidade para o esforço contínuo e fidelizado em um mesmo objeto e pelo fluxo contínuo e ininterrupto entre conteúdos e imagens. Descontinuidade e ruptura são as condições do novo processo da relação cognitiva com o mundo informativo, protagonizado pelas 
novas gerações. Em um ambiente informacional de acesso rápido, imediato, com conteúdos sempre renovados, a atenção nunca permanece por muito tempo no mesmo objeto. A dispersão é constante, e a atenção puramente superficial.

As formas de comunicação e informação são um recurso econômico básico, fonte importante de crescimento para o sistema de mercado, e também um recurso informacional, simbolicamente fulcral, que permite estruturar definições da realidade, codificar estruturas de significação e garantir a hegemonia de determinados valores ao controlar o sentido e a direção do imaginário que flui pelas conexões comunicativas. É a partir da informação e das trocas comunicacionais que se constituem as instituições e formas culturais - simbólicas e materiais - que definem o mundo social. Novos dispositivos comunicacionais em uma sociedade implicam remodelação cultural em seu seio. Assim, o motivo pelo qual os principais conflitos contemporâneos são tecidos em torno da apropriação, do controle e do monopólio da informação e dos modos de comunicação é elucidado. Se na transição para o século XXI a nova matéria-prima por excelência é o conhecimento transformado em informação - ou seja, o conhecimento digitalizado, computadorizado -, existe em torno dele um inegável conflito pelo seu controle, e em última análise, pelo poder.

Esse ambiente comunicacional contribui para uma crise da ação política, dos processos de representação política e da cultura cívica. O papel das tecnologias de informação na internacionalização dos mercados e na formação de gigantes econômicos está transformando os sistemas democráticos em algo que já não funciona segundo os moldes das democracias liberais clássicas. Se a representação política é tornar presente quem está ausente com as novas tecnologias da informação, os que necessitavam de representação passaram a representar a si mesmos de forma excessiva. No âmbito da cultura cívica, as tecnologias da informação e comunicação (TIC) são frequentemente mais coerentes com regimes de expressividade e emocionalidade das respostas do que argumentação. O exemplo do fenômeno da "shitstorm" é, nesse caso, particularmente expressivo. A palavra "shitstorm", que recentemente entrou no dicionário de referência Duden, tornou-se popular devido à projeção midiática que Angela Merkel Ihe concedeu ao usá-la em plena reunião com James Cameron em julho de 2012. O sentido atribuído ao anglicismo "shitstorm" pelo dicionário germânico prende-se com a ideia de "tempestade" de protesto e insulto, e na internet, uma autêntica avalanche de escárnio em massa. Os surtos de diabolização dos agentes políticos conhecem hoje, nesse meio, uma dimensão inusitada de visibilidade e reprodução. A definição de "shitstorm" não contém qualquer dimensão de crítica ou debate coletivo, mas a banalização do insulto em bloco na internet e manifestações de ódio coletivo, que podem tornar as redes sociais verdadeiros pelourinhos políticos virtuais.

\section{Conclusão}

O entusiasmo pelas tecnologias de comunicação reaparece sempre que uma nova invenção surge, como se dependesse da técnica a solução dos problemas culturais e sociais ou tão-só a resolução dos vícios que foram detectados na ordem dominante da mídia. A melhora do nosso conceito de comunicação terá que ser avaliada pela mudança tecnológica? Maior quantidade de informação significará melhor informação? A opulência informacional não dificultará sua triagem? Quando a difusão de certos rumos do desenvolvimento tecnológico mediatiza cada vez mais as relações sociais e as formas de exercício dos poderes, torna-se difícil conceber que nos recusaremos a perceber os interesses nele implicados. Será possível ignorar o fato de que a tecnologia tem sido o instrumento moderno de domínio econômico e político das nações mais poderosas do mundo? Acrescenta-se que seria ingênuo acreditar que a esfera pública permaneceria incólume às mutações tecnológicas, e que essas não imprimem dinâmicas e direções quanto aos aspectos essenciais da organização comunitária e da própria 
identidade coletiva. As novas estruturas tecnológicas, penetrando os circuitos de informação, implicam redefinições na economia do conhecimento, nas instâncias e nos processos deliberativos. As metamorfoses, no que diz respeito à comunicação política, repercutem-se em novas configurações de poder, representações, mecanismos de acesso e exercício.

\section{Referências Bibliográficas}

BELL, D. The coming of post-industrial society. Nova York: Basic Books, 1973.

. The end of ideology: on the exhaustion of political ideas in the fifties. Nova York: Free Press, 1960.

BRETON, P. L'utopie de la communication. Paris: La Découverte, 1992.

DUNNING, J. H. Regions, globalization and the knowledge-based economy. Oxford: Oxford University Press, 2000.

LEADBEATER, C. Knowledge economy. Londres: Penguin Group, 1999.

MACHLUP, F. The production and distribution of knowledge in the United States. New Jersey: Princeton University Press, 1962.

MASUDA, Y. The information society as post-industrial society. Bethesda: World Futures Society, 1980.

MARTINS, H.; GARCIA, J. L. Web. In: CARDOSO, J. L.; MAGALHÃES, P.; PAIS, J. M. Portugal social de A a Z. Temas em aberto. Lisboa: Impresa Publishing/Expresso, 2013. p. 285-293.

MATTELART, A. La communication-monde: histoire des idées et des stratégies. Paris: La Découverte, 1999.

NORRIS, P. Digital divide? Civic engagement, information poverty and the internet worldwide. Cambridge: Cambridge University Press, 2001.

PARK, R. E. The natural history of the newspaper. American Journal of Sociology, v. 29, n. 3, p. 273-289, 1923.

PORAT, M. U.; RUBIN, M. R. The informationeconomy: definitions and measurement. Washington: Department of Commerce, Office of Telecommunications, 1977.

PROULX, S. Interroger la métaphore d'une société de l'information: horizon et limites d'une utopie. In: THÉORÊT, Y. (Org.). David contre Goliath. La convention sur la protection et la promotion de la diversité des expressions culturelles de I'UNESCO. Montréal: Éditions HMH Hurtubise, 2008. p. 99-124.

RAMONET, I. Internet, los nuevos caminos de la comunicación. Madrid: Alianza Editorial, 1998.

. La tyrannie de la communication. Paris: Gallimard, 2001.

RÉNAULD, P.; TORRES, A. Una oportunidad para el Sur. In: RAMONET, I. (Org.). Internet, los nuevos caminos de la comunicación. Madrid: Alianza Editorial, 1998. p. 137-146.

STEHR, N. Knowledge societies. Londres: Sage Publications, 1994.

WIENER, N. The human use of human beings: cybernetics and society. Nova York: Doubleday Anchor, 1954. 